\title{
Effects of hypercapnia and NO synthase inhibition in sustained hypoxic pulmonary vasoconstriction
}

\author{
Farzaneh Ketabchi ${ }^{1}$, Hossein A Ghofrani ${ }^{2}$, Ralph T Schermuly ${ }^{2}$, Werner Seeger ${ }^{2}$, Friedrich Grimminger ${ }^{2}$, \\ Bakytbek Egemnazarov ${ }^{2}$, S Mostafa Shid-Moosavi ${ }^{1}$, Gholam A Dehghani ${ }^{1}$, Norbert Weissmann ${ }^{2^{*}}$ and \\ Natascha Sommer ${ }^{2}$
}

\begin{abstract}
Background: Acute respiratory disorders may lead to sustained alveolar hypoxia with hypercapnia resulting in impaired pulmonary gas exchange. Hypoxic pulmonary vasoconstriction (HPV) optimizes gas exchange during local acute (0-30 min), as well as sustained (> $30 \mathrm{~min}$ ) hypoxia by matching blood perfusion to alveolar ventilation. Hypercapnia with acidosis improves pulmonary gas exchange in repetitive conditions of acute hypoxia by potentiating HPV and preventing pulmonary endothelial dysfunction. This study investigated, if the beneficial effects of hypercapnia with acidosis are preserved during sustained hypoxia as it occurs, e.g in permissive hypercapnic ventilation in intensive care units. Furthermore, the effects of NO synthase inhibitors under such conditions were examined.
\end{abstract}

Method: We employed isolated perfused and ventilated rabbit lungs to determine the influence of hypercapnia with or without acidosis ( $\mathrm{pH}$ corrected with sodium bicarbonate), and inhibitors of endothelial as well as inducible NO synthase on acute or sustained HPV (180 min) and endothelial permeability.

Results: In hypercapnic acidosis, HPV was intensified in sustained hypoxia, in contrast to hypercapnia without acidosis when HPV was amplified during both phases. L-N ${ }^{G}$-Nitroarginine (L-NNA), a non-selective NO synthase inhibitor, enhanced acute as well as sustained HPV under all conditions, however, the amplification of sustained HPV induced by hypercapnia with or without acidosis compared to normocapnia disappeared. In contrast 1400 W, a selective inhibitor of inducible NO synthase (iNOS), decreased HPV in normocapnia and hypercapnia without acidosis at late time points of sustained HPV and selectively reversed the amplification of sustained HPV during hypercapnia without acidosis. Hypoxic hypercapnia without acidosis increased capillary filtration coefficient (KfC). This increase disappeared after administration of $1400 \mathrm{~W}$.

Conclusion: Hypercapnia with and without acidosis increased HPV during conditions of sustained hypoxia. The increase of sustained HPV and endothelial permeability in hypoxic hypercapnia without acidosis was iNOS dependent.

Keywords: hypoxia, hypercapnia, acidosis, nitric oxide, hypoxic pulmonary vasoconstriction

\footnotetext{
* Correspondence: norbert.weissmann@innere.med.uni-giessen.de

${ }^{2}$ Justus-Liebig-University Giessen, University of Giessen \& Marburg Lung Center (UGMLC), Excellence Cluster Cardio-Pulmonary System (ECCPS),

Medical Clinic II/IV/V, Aulweg 130, 35392 Giessen, Germany

Full list of author information is available at the end of the article
} 


\section{Background}

Acute and chronic respiratory disorders show a high incidence and a high mortality rate of 40-60\% worldwide [1-3]. Acute respiratory dysfunctions as occurring in intensive care under conditions like the adult respiratory distress syndrome, lung edema or pneumonia, as well as acute exacerbations of chronic obstructive lung disease or acute neuromuscular damage may induce local or global alveolar hypoxia and hypercapnia. Moreover, hypercapnia is a common condition in the therapeutic approach of permissive hypercapnic ventilation for the treatment of patients with acute lung injury [1]. More than six decades ago it has been concluded by von Euler and Liljestrand that alveolar hypoxia induces HPV for ventilation-perfusion matching in the lung [4]. HPV is the physiological response of precapillary vessels exposed to acute (0-30 min), as well as sustained alveolar hypoxia (> $30 \mathrm{~min}$ ), in order to improve pulmonary gas exchange under conditions of local hypoxia [5]. Sustained HPV may result in the development of acute pulmonary hypertension under conditions of general alveolar hypoxia. However, it is still controversial how hypercapnia or acidosis affects pulmonary vascular tone and hypoxic vasconstriction. Whereas evidence exists that metabolic acidosis increases pulmonary arterial pressure (PAP), there are inconsistent findings as to whether hypercapnic acidosis has any effect on pulmonary arterial pressure [6-8]. Some reports have pointed out that in isolated lung preparations hypercapnia with normal $\mathrm{pH}$ increases, whereas others suggested that it does not change pulmonary vascular tone [9-12].

We recently showed, that hypercapnic acidosis amplified the acute phase of HPV (lasting up to 10 minutes) and improved ventilation-perfusion matching [13], but it is still unknown, if this is true in pathological conditions of sustained hypoxia lasting much more than minutes and at least several hours. In this regard it is important to mention that the acute phase and the sustained phase of HPV are suggested to be regulated, at least in part, by different mechanisms $[13,14]$. In addition, the sustained phase may be clinically more relevant, as the conditions of repiratory dysfunction, as detailed above, can lead to conditions of prolonged hypoxia, lasting longer than several minutes [15]. Besides a possible deterioration of ventilation-perfusion matching, disturbance of pulmonary gas exchange might be aggravated by development of pulmonary edema during exposure to prolonged hypoxia with hypercapnia.

Nitric oxide (NO) is known as an important modulator of HPV. However, its detailed role for the effects of hypercapnia on HPV is unknown $[16,17]$. Both, a decrease of NO production during hypercapnia [18-20], as well as an increase in NO production [21-23] has been shown. It was also suggested that the NO production does not change or does not contribute to the regulation of pulmonary vascular tone at above conditions [12,24]. Particularly, 1) the general role of NO synthases (NOS), 2) a differentiation between the role of endothelial NOS (eNOS) and inducible NOS (iNOS), as well as 3) effects of NO synthase inhibitors (L-NNA and $1400 \mathrm{~W}$, respectively) on sustained HPV under hypercapnia have not been investigated yet.

Against this background, we 1) compared the effects of hypercapnia with or without acidosis on HPV and endothelial permeability under conditions of acute and sustained hypoxia and 2) deciphered the potential therapeutic effects of NO inhibitors in such conditions. Our investigations were performed in isolated, perfused and ventilated rabbit lungs, a model that allows detailed quantification of pulmonary hemodynamic and biochemical events without interference with systemic regulatory mechanisms.

\section{Methods}

Lung isolation, perfusion, and ventilation

Animal experiments were approved by the local authorities (Regierungspräsidium Giessen) in Germany. The model of isolated perfused rabbit lungs has been described previously [25]. Briefly, pathogen free male rabbits (body weight $2.8-3.8 \mathrm{~kg}$ ) were deeply anaesthetized with an i.v. application of ketamine $(30-50 \mathrm{mg} / \mathrm{kg}$ ) and xylazine $(6-10 \mathrm{mg} / \mathrm{kg})$ and treated with the anticoagulant heparin (1000 U/kg body weight). The trachea was cannulated and animals were ventilated with room air (tidal volume $30 \mathrm{ml}$, frequency 30 strokes $/ \mathrm{min}$ ). The lungs were perfused with Krebs-Henseleit solution (perfusate) through the pulmonary artery. After rinsing the lungs with 1 liter of the perfusate for washout of the blood, the perfusion circuit was closed for circulation and the start of the experiments. Meanwhile, the flow rate was slowly increased from 20 to $150 \mathrm{ml} / \mathrm{min}$, and concomitantly the left atrial pressure was set at 2 mmHg. A positive end expiratory pressure of $2 \mathrm{~cm} \mathrm{H}_{2} \mathrm{O}$ was chosen for prevention of regional alveolar collapse.

The isolated perfused lung was placed in a temperature equilibrated housing chamber and freely suspended from a force transducer (Hottinger Baldwin, Germany) for continuous monitoring of organ weight. The whole system (perfusate, reservoirs, tubing, and housing chamber) was heated to $38.5^{\circ} \mathrm{C}$. Pressures in the pulmonary artery, left atrium, and trachea were continuously registered. All lungs included in the study 1) exhibited a homogeneous white appearance with no signs of hemostasis, edema, or atelectasis, 2) revealed a constant mean pulmonary artery and peak ventilation pressures in the normal range, and 3 ) were isogravimetric during the first 20 min of steady state period. Because flow-rate of the perfusate was constant, changes in pulmonary artery pressure are proportional to pulmonary vascular resistance. 


\section{Composition of ventilatory gas and perfusate}

Four different gas mixtures were employed for ventilation of the lung during different experimental conditions (Gas Mixing Chamber, KM 60-3/6MESO, Witt, Witten, FRG, Germany): 1) normoxia plus normocapnia: $21.0 \%$ $\mathrm{O}_{2}, 5.3 \% \mathrm{CO}_{2}$ balanced with $\mathrm{N}_{2}, 2$ ) normoxia plus hypercapnia: $21.0 \% \mathrm{O}_{2}, 11.0 \% \mathrm{CO}_{2}$, balanced with $\mathrm{N}_{2}, 3$ ) hypoxia plus normocapnia: $3.0 \% \mathrm{O}_{2}, 5.3 \% \mathrm{CO}_{2}$ balanced with $\mathrm{N}_{2}, 4$ ) hypoxia plus hypercapnia: $3.0 \% \mathrm{O}_{2}, 11.0 \%$ $\mathrm{CO}_{2}$ balanced with $\mathrm{N}_{2}$. The perfusate used for the study contained $120.0 \mathrm{mM} \mathrm{NaCl}, 1.1 \mathrm{mM} \mathrm{K}_{2} \mathrm{HPO}_{4}, 1.3 \mathrm{mM}$ $\mathrm{MgCl}_{2}, 4.3 \mathrm{mM} \mathrm{KCl}, 2.4 \mathrm{mM} \mathrm{CaCl} 2,13.3 \mathrm{mM}$ glucose, 50 g hydroxy-ethyl-amylopectin (MW: 200000). In nonacidotic experiments $\mathrm{pH}$ was adjusted with $\mathrm{NaHCO}_{3}$ (sodium-bicarbonate $1 \mathrm{M} 8.4 \%$ [Serag-Wiessner KG]) to a physiological range of 7.35-7.40.

In all groups, $\mathrm{PO}_{2}, \mathrm{PCO}_{2}$ and $\mathrm{pH}$ of the perfusate were measured with a gas analyzer 10 min after starting the experiment and then, 10 min after initiating experimental conditions. Table 1 shows the values taken 10 min after initiating each experimental condition. The values of $\mathrm{PO}_{2}, \mathrm{PCO}_{2}$ and $\mathrm{pH}$ remained stable during the time course of each experiment.

\section{Gravimetric determination of capillary filtration coefficient}

Capillary filtration coefficient $\left(\mathrm{K}_{\mathrm{fc}}\right)$ was quantified to assess changes in capillary permeability by a hydrostatic challenge. It was determined gravimetrically from the slope of the lung weight-gain curve induced by a stepwise elevation of venous pressure by $5.5 \mathrm{mmHg}$ for 8 minutes, as described previously [26].

\section{Evaluation of exhaled NO}

The technique of measurement of exhaled NO levels has been described previously [17]. In brief, an aliquot of the mixed expired gas was continuously forwarded to a chemiluminescence NO analyzer (280 NOA; Sievers Instruments, Boulder, $\mathrm{CO}$ ) to measure exhaled $\mathrm{NO}$ concentration.

\section{Study protocol}

Forty minutes after the establishment of normoxic normocapnic ventilation, the first hydrostatic challenge was performed by elevating pulmonary venous outflow pressure from 2.0 to $7.5 \mathrm{mmHg}$ for $8 \mathrm{~min}$. Fifteen minutes later, a $10 \mathrm{~min}$ period of hypoxic ventilation was performed to determine the response to alveolar hypoxic normocapnia, in order to ensure comparable vasoreactive potential of the pulmonary vasculature of the individual lungs. Subsequently, hypoxic normocapnic ventilation of the lung was changed to 15 min normoxic normocapnic ventilation. Thereafter, each lung was randomly ventilated for $180 \mathrm{~min}$ (0-30 min: acute phase, 30-180 min: sustained phase) with different gas mixtures as described above (please refer to: experimental conditions) followed by 10 min normoxic normocapnic ventilation (180-190 min: recovery phase). Thirty minutes later, a second $\mathrm{K}_{\mathrm{fc}}$ measurement was performed. In the pharmocologically treated groups, L-NNA $(200 \mu \mathrm{M})$ or $1400 \mathrm{~W}(2 \mu \mathrm{M})$ was added to the perfusate $10 \mathrm{~min}$ prior to the onset of the first hydrostatic challenge.

\section{Statistical Analysis}

Data are given as mean \pm SEM. Analysis of variance (ANOVA) with the Student-Newman-Keuls (SNK) post hoc test was used for comparison of more than two groups. For comparison of the values during the time course of one group, one way ANOVA for repeated measurements with SNK post hoc analysis was used. For the comparison of two groups a Student's t-test was applied. Significance was assumed for $\mathrm{P}<0.05$.

\section{Results}

Effect of hypercapnia with and without acidosis on HPV in the presence and the absence of L-NNA and $1400 \mathrm{~W}$ Mean normoxic normocapnic pulmonary artery pressure (PAP) values prior to the onset of hypoxia were $10.0 \pm$ $1.5 \mathrm{mmHg}(\mathrm{n}=7)$. During hypoxic normocapnia, the initial increase of PAP $(\triangle \mathrm{PAP})$ reached the maximum value of $4.0 \pm 0.5 \mathrm{mmHg}$ at $6 \mathrm{~min}$ after induction of

Table $1 \mathrm{pH}, \mathrm{PCO}_{2}, \mathrm{PO}_{2}$ and $\left[\mathrm{HCO}_{3}^{-}\right]$in the perfusate during the different experimental conditions

\begin{tabular}{|c|c|c|c|c|c|c|}
\hline Parameters & $\begin{array}{l}\text { Normoxic } \\
\text { normocapnia }\end{array}$ & $\begin{array}{l}\text { Normoxic } \\
\text { hypercapnic } \\
\text { acidosis }\end{array}$ & $\begin{array}{l}\text { Normoxic } \\
\text { hypercapnia } \\
\text { w/o acidosis }\end{array}$ & $\begin{array}{l}\text { Hypoxic } \\
\text { normocapnia }\end{array}$ & $\begin{array}{l}\text { Hypoxic } \\
\text { hypercapnic } \\
\text { acidosis }\end{array}$ & $\begin{array}{l}\text { Hypoxic } \\
\text { hypercapnia } \\
\text { w/o acidosis }\end{array}$ \\
\hline $\mathrm{PO}_{2}(\mathrm{mmHg})$ & $158 \pm 2$ & $162 \pm 1$ & $165 \pm 0$ & $51 \pm 7 *$ & $62 \pm 1 *$ & $64 \pm 1 *$ \\
\hline $\mathrm{PCO}_{2}(\mathrm{mmHg})$ & $37 \pm 0$ & $71 \pm 1 *$ & $72 \pm 0$ * & $37 \pm 0$ & $72 \pm 0 *$ & $72 \pm 1 *$ \\
\hline $\mathrm{pH}$ & $7.38 \pm 0.00$ & $7.08 \pm 0.00 *$ & $7.38 \pm 0.00$ & $7.36 \pm 0.00$ & $7.09 \pm 0.00 *$ & $7.38 \pm 0.00$ \\
\hline [HCO3] $(\mathrm{mmol} / \mathrm{L})$ & $21 \pm 0$ & $21 \pm 0$ & $42 \pm 0 *$ & $20 \pm 0$ & $21 \pm 0$ & $41 \pm 0$ * \\
\hline
\end{tabular}

Data are mean \pm SEM for $n=5-8$ experiments each, derived 10 min after initiating each experimental condition. No difference of the respective parameters could be detected during the course of the experiment (data not shown). In hypercapnia with normal $\mathrm{pH}$, $\mathrm{pH}$ was corrected to the given values by the addition of sodium bicarbonate.

* indicates significant differences as compared to normoxia or normocapnia. 
A

\section{$\begin{array}{lll}\text { Acute phase } & \text { Sustained phase } & \text { Recovery }\end{array}$}

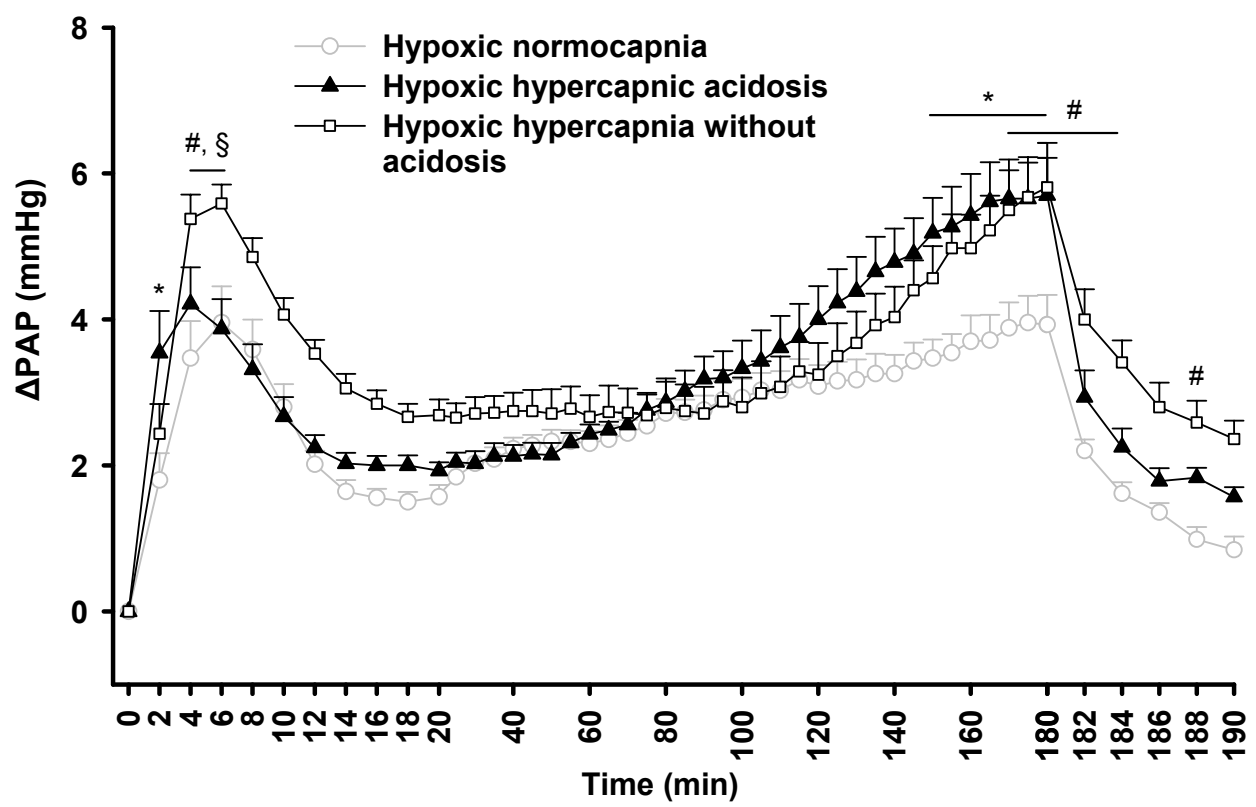

B

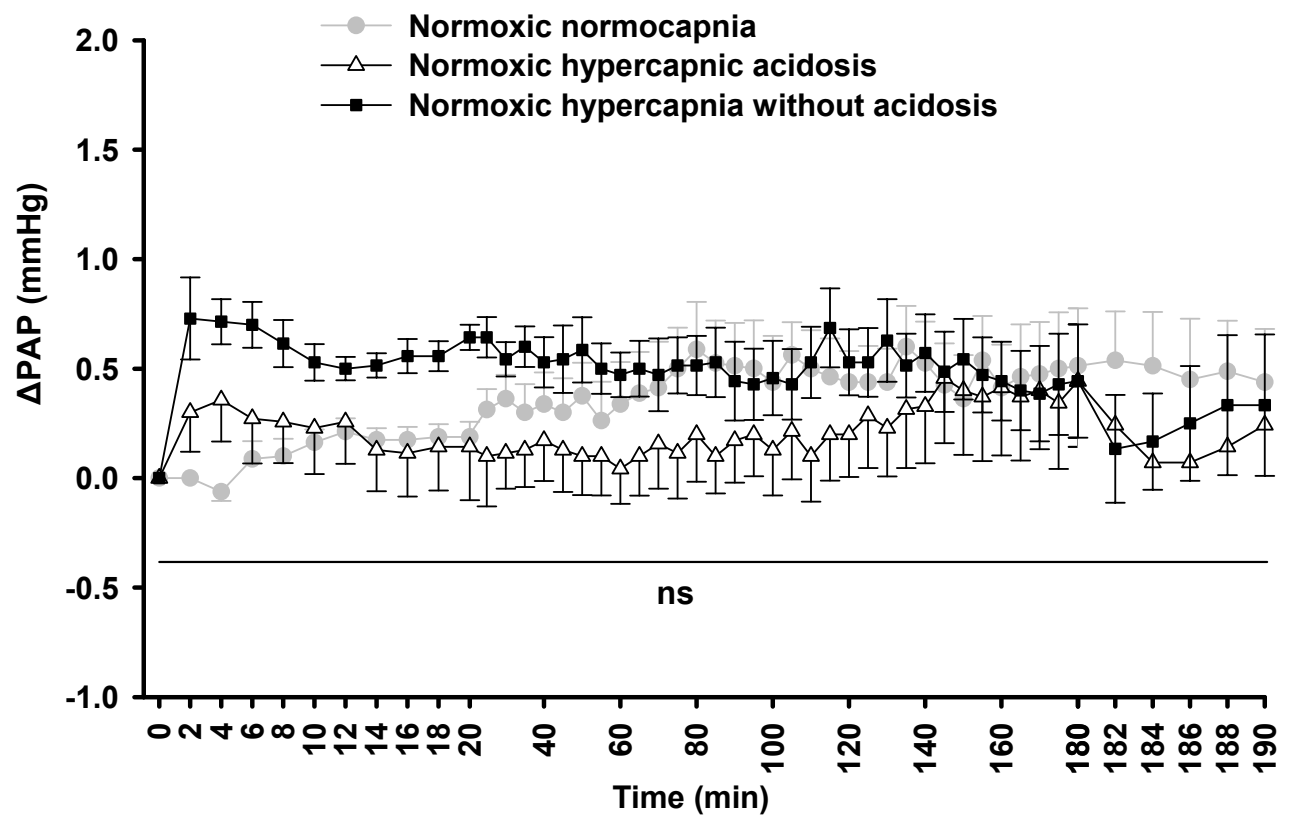

Figure 1 Effects of hypercapnia with or without acidosis on changes in pulmonary arterial pressure ( $\triangle \mathrm{PAP}$ ) during hypoxia, and normoxia. A. Changes of PAP in hypoxic normocapnia $(n=7)$, hypoxic hypercapnic acidosis $(n=7)$, and hypoxic hypercapnia without acidosis $(n=8)$ during 180 min of hypoxic ventilation, followed by 10 min ventilation with normoxic normocapnic gas (recovery). $\triangle P A P$ : change of PAP referenced to the baseline value at time set at zero. B. Changes of PAP in normoxic normocapnia $(n=8)$, normoxic hypercapnic acidosis $(n=8)$ and normoxic hypercapnia without acidosis $(n=7)$ during 190 min normoxic ventilation. $\triangle P A P$ : change of PAP referenced to the value at time set at zero. All data are mean \pm SEM. ${ }^{*}$, significant difference $(P<0.05)$ between hypoxic normocapnia and hypoxic hypercapnic acidosis. \#, significant difference $(P<0.05)$ between hypoxic normocapnia and hypoxic hypercapnia without acidosis. $\S$, significant difference $(P<0.05)$ between hypoxic hypercapnic acidosis and hypoxic hypercapnia without acidosis. 
hypoxia ("acute phase"), was followed by a decline to a $\triangle \mathrm{PAP}$ of $1.6 \pm 0.2 \mathrm{mmHg}$ at minute 14 , and then remained stable up to minute 18 . Subsequently, in the sustained phase of HPV, $\triangle$ PAP was gradually elevated reaching a maximum value of $4.0 \pm 0.4 \mathrm{mmHg}$ at 175 min ("sustained phase", Figure 1A).

Mean normoxic normocapnic PAP values before the onset of hypoxic hypercapnic acidosis were $10.1 \pm 0.5$ $\mathrm{mmHg}(\mathrm{n}=7)$. Ventilation with hypoxic hypercapnic acidosis resulted in an enhancement of the sustained phase of HPV compared to normocapnia, $\triangle \mathrm{PAP}$ ranged from $5.2 \pm 0.5 \mathrm{mmHg}$ at minute 150 to $5.7 \pm 0.5$ $\mathrm{mmHg}$ at minute 180 , whereas the maximal strength of HPV during the acute phase ( $\triangle \mathrm{PAP} 4.2 \pm 0.5 \mathrm{mmHg}$ at minute 4) was unchanged, but showed a faster rise (3.5 $\pm 0.6 \mathrm{mmHg}$ during hypoxic hypercapnic acidosis vs. 1.8 $\pm 0.4 \mathrm{mmHg}$ during hypoxic normocapnia at minute 2 ) (Figure 1A).

Mean normoxic normocapnic PAP values before the onset of hypoxic hypercapnia without acidosis were 9.9 $\pm 0.4 \mathrm{mmHg}(\mathrm{n}=7)$. Correction of acidosis with sodium bicarbonate in the hypoxic hypercapnia without acidosis, resulted in increased HPV during the acute as well as the sustained phase compared to hypoxic normocapnia.
The initial strong vasoconstrictive response (maximum value of $5.6 \pm 0.3 \mathrm{mmHg}$ at $6 \mathrm{~min}$ of exposure) declined to $2.7 \pm 0.2 \mathrm{mmHg}$ at $18 \mathrm{~min}$. There was no significant difference between the values of $\triangle \mathrm{PAP}$ during the sustained phase of the maneuvers in the hypoxic hypercapnic with or without acidosis groups (Figure 1A).

There were no significant changes in normoxic pressure during the course of the experiments in normoxic normocapnia or normoxic hypercapnia with or without acidosis groups (Figure 1B).

Hypoxia led to a reduced lung weight during all three conditions compared to normoxia. In hypoxia, the decremental changes of lung weight during 5-15 min were larger in the hypoxic hypercapnia without acidosis group than the hypoxic normocapnic group, but no difference was detectable between hypoxic normocapnia and hypoxic hypercapnic acidosis (Figure 2).

In the presence of L-NNA, no significant changes of pulmonary artery pressure were detectable under normoxic ventilation, although a tendency towards higher values at later time points was evident (Figure $3 \mathrm{~A}, \mathrm{~B}, \mathrm{C}$ ). Treatment with $1400 \mathrm{~W}$ did neither change normoxic normocapnic PAP nor PAP during normoxic hypercapnic acidosis compared to the untreated group (Figure
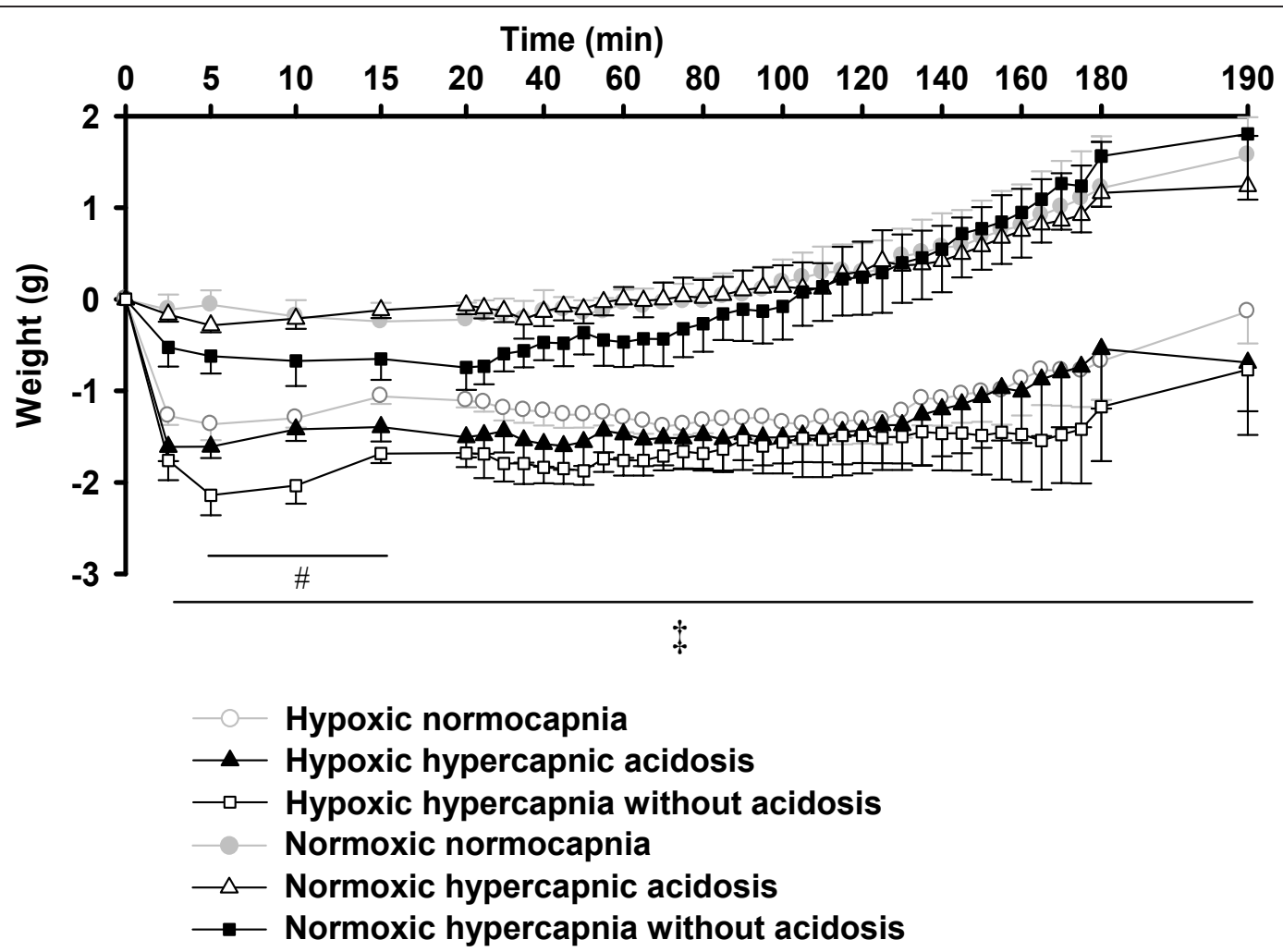

Figure 2 Effects of hypercapnia with or without acidosis on changes in lung weight during hypoxia, and normoxia. Lung weight changes of the respective experiments of figure 1. All data are mean \pm SEM. \#, significant difference $(P<0.05)$ between hypoxic normocapnia and hypoxic hypercapnia without acidosis. $\neq$, significant difference $(P<0.05)$ between hypoxic groups and normoxic normocapnia. 
3D, E). However, during normoxic hypercapnia without acidosis $1400 \mathrm{~W}$ induced a significant PAP decrease at min 4-6 and an increase at min 55-65 compared to lungs in the absence of $1400 \mathrm{~W}$ (Figure 3F).

In the presence of L-NNA, the acute and sustained phase of HPV was increased in all groups (Figure 4A, B, C). In contrast, $1400 \mathrm{~W}$ decreased the sustained phase of HPV at late time points in normocapnia and hypoxic hypercapnia without acidosis, but not in hypoxic hypercapnic acidosis compared to the respective controls in the absence of $1400 \mathrm{~W}$ (Figure 4D, E, F).

For better visualization of the effect of hypercapnia on $\mathrm{HPV}$ in the presence of L-NNA or $1400 \mathrm{~W}, \triangle \mathrm{PAP}$ values of the normocapnic and hypercapnic groups from Figure 3 and 4 are displayed in Figure 5A/B and 7A/B in a direct comparison. In the presence of L-NNA the effects of hypercapnia on acute HPV were similar (Figure $5 \mathrm{~A}$ ) as in the absence of L-NNA (Figure 1A) but the increase in sustained hypoxia was no longer significant, compared to hypoxic normocapnia. Normoxic values were not different between the groups in presence of LNNA (Figure 5B). Moreover, during L-NNA treatment the lung weights showed no difference between hypoxic groups (Figure 6). In presence of $1400 \mathrm{~W}, \triangle \mathrm{PAP}$ was increased in sustained hypoxic hypercapnic acidosis at 150-182 min, but not in hypercapnia without acidosis compared to hypoxic normocapnia. Acute HPV was still increased (minutes 4-16) during hypoxic hypercapnia without acidosis compared to hypoxic normocapnia, similar to the effect in the absence of $1400 \mathrm{~W}$ (Figure 7A). Normoxic values were not different between the groups in presence of $1400 \mathrm{~W}$ (Figure 7B). Moreover, during $1400 \mathrm{~W}$ treatment the lung weights showed no difference between hypoxic groups (Figure 8).

\section{Effect of hypoxia, hypercapnia with and without acidosis on NO production}

In normoxic normocapnia, exhaled NO decreased gradually reaching a minimum of $73 \pm 2 \%$ of its baseline value at $180 \mathrm{~min}$ of normoxic ventilation. In normoxic hypercapnia with or without acidosis, exhaled NO declined immediately to $79 \pm 1 \%$ and $82 \pm 1 \%$ of the respective baseline values within 2 min of normoxic hypercapnic ventilation, respectively and remained significantly lower than the normocapnic group up to 100 min of the experiment. In hypoxic normocapnia, the exhaled NO rapidly decreased to $86 \pm 3 \%$ of its baseline value within 2 min of hypoxic ventilation, reached $66 \pm$ $3 \%$ of its baseline value at $180 \mathrm{~min}$ of hypoxic ventilation and was significantly different from normoxic normocapnia during the entire period of hypoxic ventilation. In hypoxic hypercapnia with or without acidosis exhaled NO dropped to $66 \pm 1 \%$ and $71 \pm 1 \%$ of their baseline values, respectively, within 2 min of the experiment. The exhaled NO values during the entire period of the experiment in both hypoxic hypercapnia groups were significantly lower than those of the normoxic groups, as well as compared to hypoxic normocapnia (Figure 9).

\section{Effect of hypoxia, hypercapnia with and without acidosis on endothelial permeability in the presence and the absence of L-NNA and $1400 \mathrm{~W}$}

The post-hypoxia $K_{\mathrm{fc}}$ value was significantly higher in hypoxic hypercapnia without acidosis than in hypoxic normocapnia and normoxic normocapnia, as well as compared to its own pre-hypoxic value (Figure 10). This effect was no longer detectable in the presence of 1400 $\mathrm{W}$, but was still detectable in the presence of L-NNA (Figure 10F). Post-hypoxic $\mathrm{K}_{\mathrm{fc}}$ values of the other groups were not different between each other and from their own pre-hypoxic values (Figure 10A, B, C, D, E).

\section{Discussion}

Although it is known for decades that alveolar hypoxia induces HPV, the effects of hypercapnia on pulmonary vascular tone and capillary permeability under sustained hypoxia, are still not fully elucidated. In addition, the role of NO signaling under such conditions is not fully understood yet. HPV is essential to optimize pulmonary gas exchange during local acute and prolonged hypoxia. As previously shown by our group, hypercapnia was concluded to be beneficial for ventilation-perfusion matching in conditions of repetitive acute hypoxic episodes, each lasting up to 10 minutes. Hypercapnic acidosis improved arterial $\mathrm{pO}_{2}$, and augmented HPV without affecting endothelial permeability [13]. In extension of these investigations we now focused on the effects of sustained hypoxic hypercapnia on HPV and pulmonary endothelial permeability. Furthermore, we addressed the role of endothelial and inducible NO synthases in prolonged hypoxic hypercapnia.

Our data revealed that during sustained hypoxia both hypercapnia with and hypercapnia without acidosis increased HPV. However, only hypercapnia without acidosis enhanced acute HPV in the first minutes of the hypoxic ventilation, as shown for short term hypoxia in our previous study [13]. This finding is reminiscent of the effect of hypercapnia on repetitive episodes of short term HPV, when hypercapnia without acidosis increased acute HPV during the first repetitive hypoxic maneuvers, but hypercapnia with acidosis enhanced HPV only in the late episodes of repetitive hypoxic maneuvers [13]. It is also in line with findings that hypercapnic acidosis caused a marked increase in pulmonary vascular resistance during a time period of 60-80 min hypoxia, but not at earlier time points [27]. However, with regard to the effect of hypercapnia on HPV, there are 
$\mathrm{D}$

A

Acute phase Sustained phase Recovery

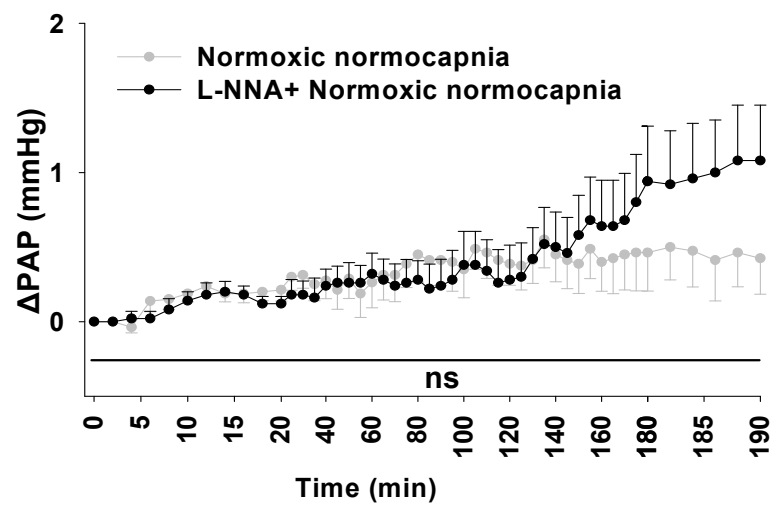

$\mathrm{B}$

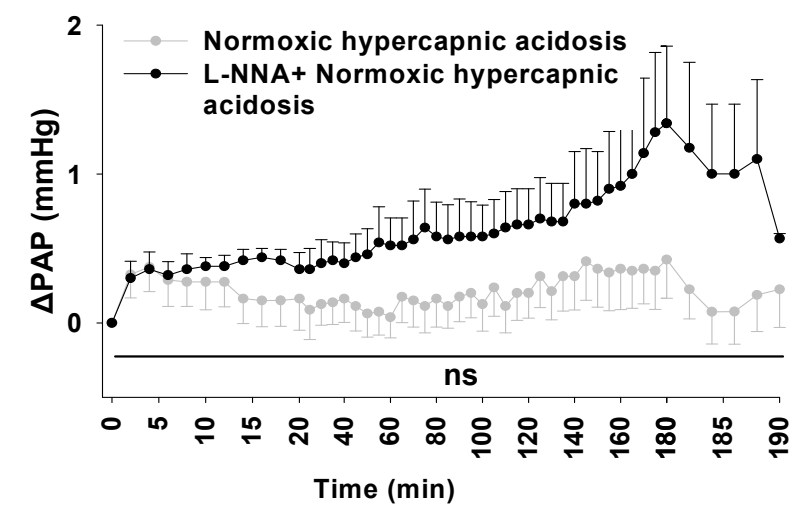

$\mathrm{C}$

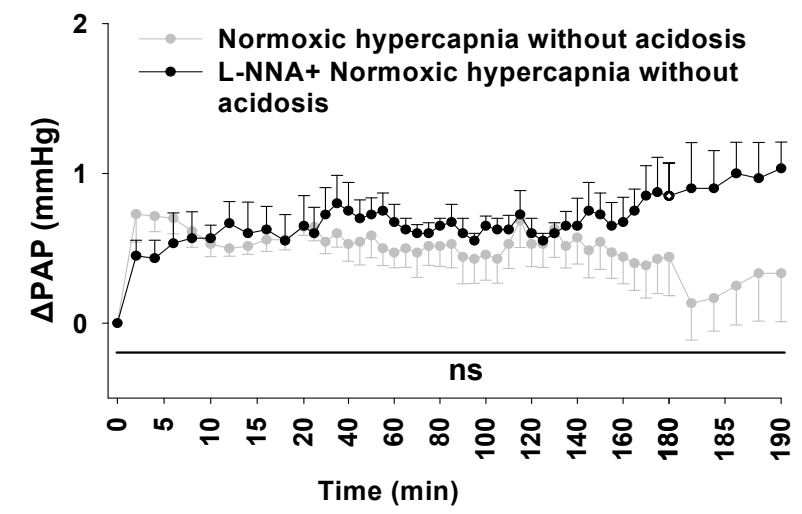

Acute phase Sustained phase Recovery

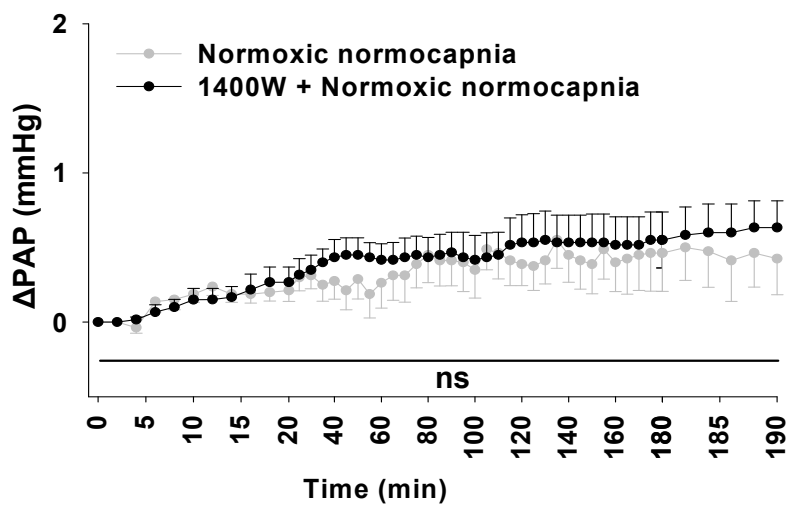

E

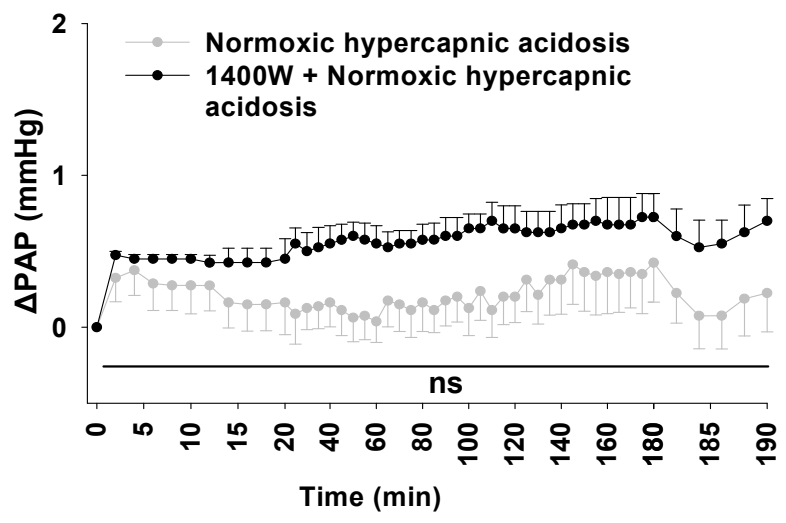

$\mathrm{F}$

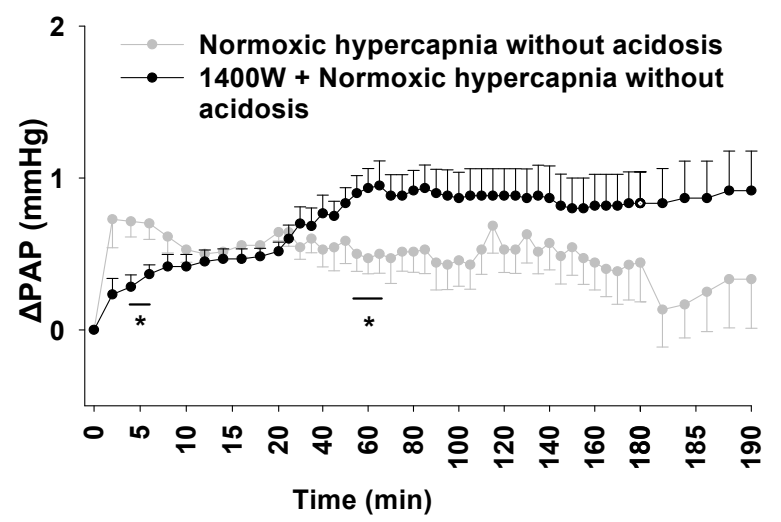

Figure 3 Effects of L-N $\mathrm{N}^{\mathrm{G}}$-Nitroarginine (L-NNA) and N-([3-(Aminomethyl) phenyl] methyl) ethanimidamide dihydrochloride (1400 W) on pulmonary vascular tone during normoxic ventilation. Normoxic $\triangle P A P$ values in the absence of L-NNA and $1400 \mathrm{~W}$ are identical to those depicted in Figure 1. A. L-NNA-treated normoxic normocapnia $(n=5)$, B. L-NNA-treated normoxic hypercapnic acidosis $(n=5), \mathbf{C}$. L-NNA-treated normoxic hypercapnia without acidosis $(n=4), \mathbf{D} .1400 \mathrm{~W}$-treated normoxic normocapnia $(n=6), \mathbf{E} .1400 \mathrm{~W}$-treated normoxic hypercapnic acidosis $(n=4), F$. 1400 W-treated normoxic hypercapnia without acidosis $(n=6)$ compared to $\triangle P A P$ from lungs in the absence of $L-N N A$ or $1400 \mathrm{~W}$ during $190 \mathrm{~min}$ of normoxic ventilation. $\triangle \mathrm{PAP}$ : change of PAP referenced to the value at time set at zero. Data are mean \pm SEM. * significant difference $(P<0.05)$ between treated and untreated groups. 


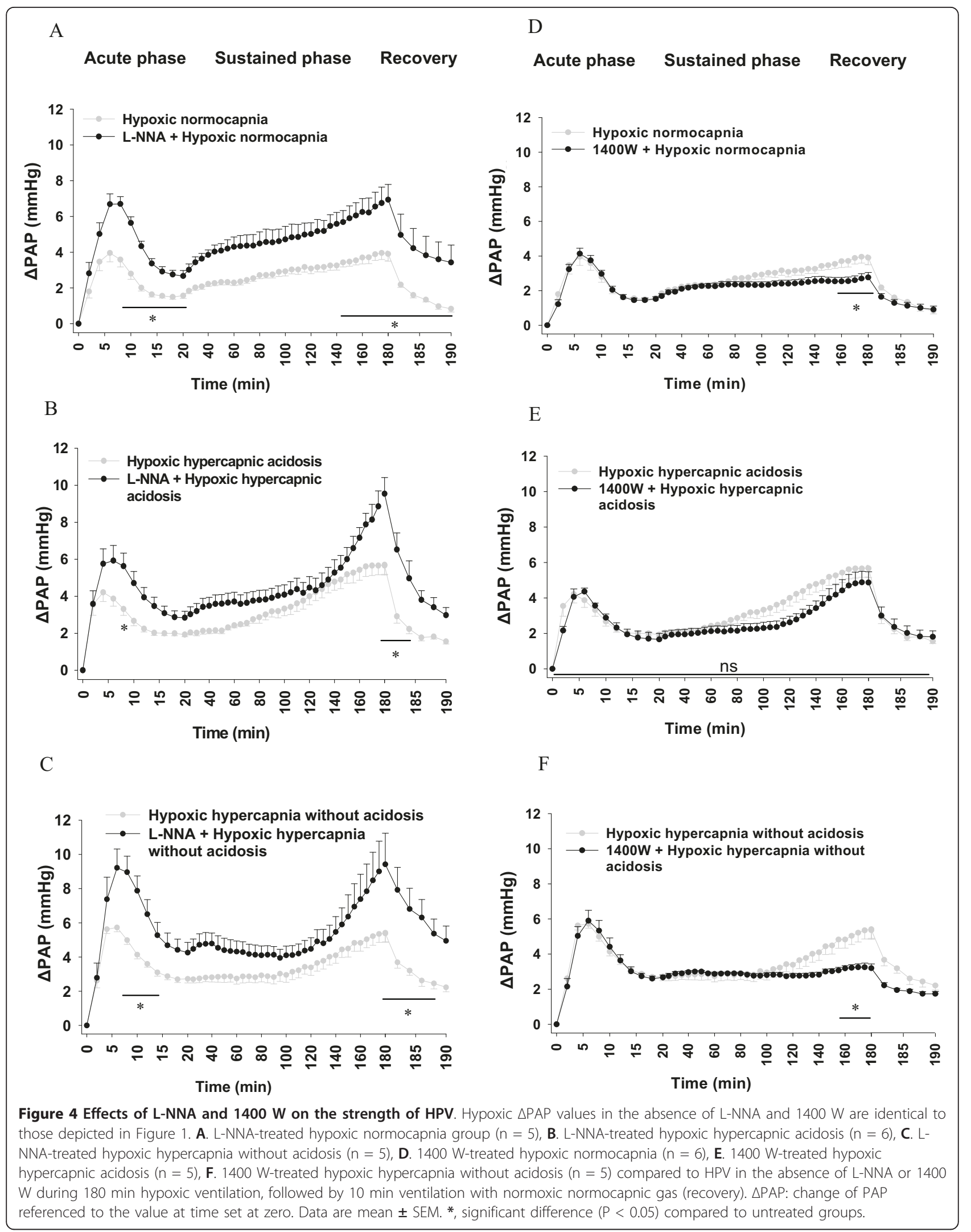


A
Acute phase
Sustained phase
Recovery

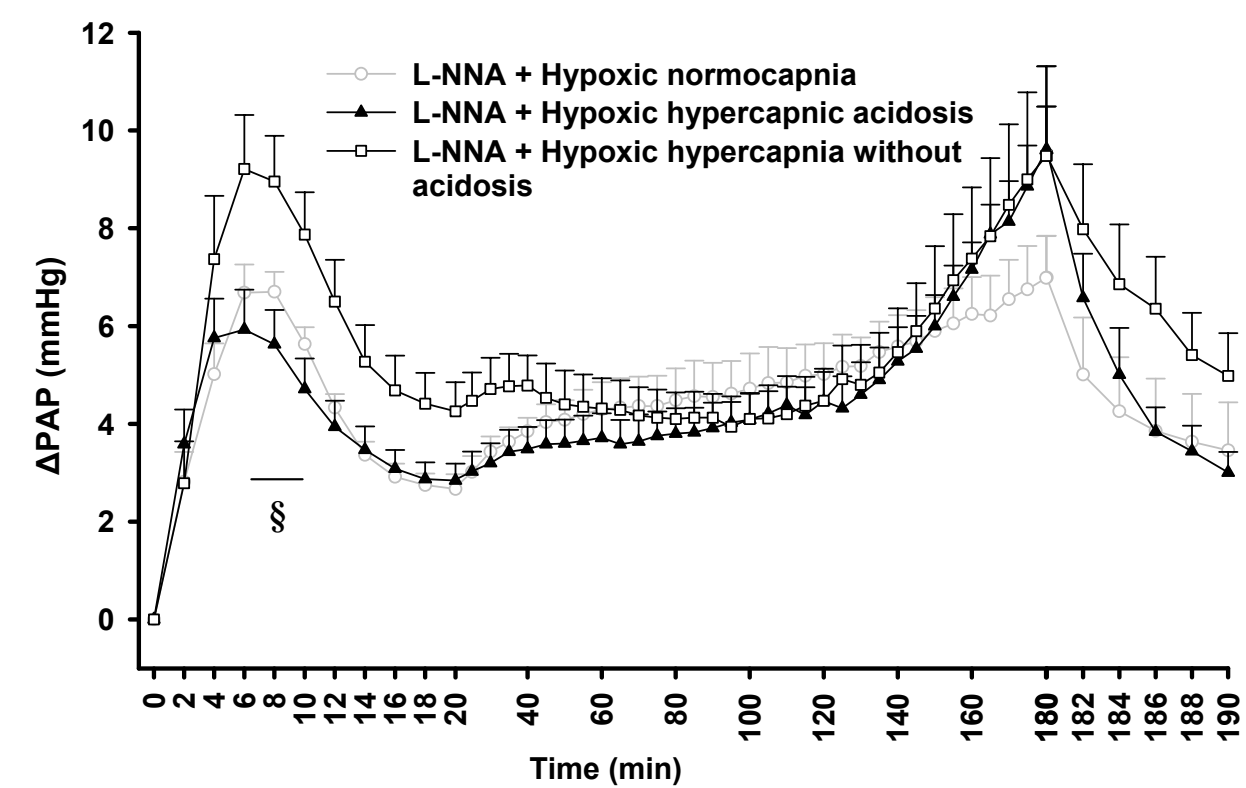

$\mathrm{B}$

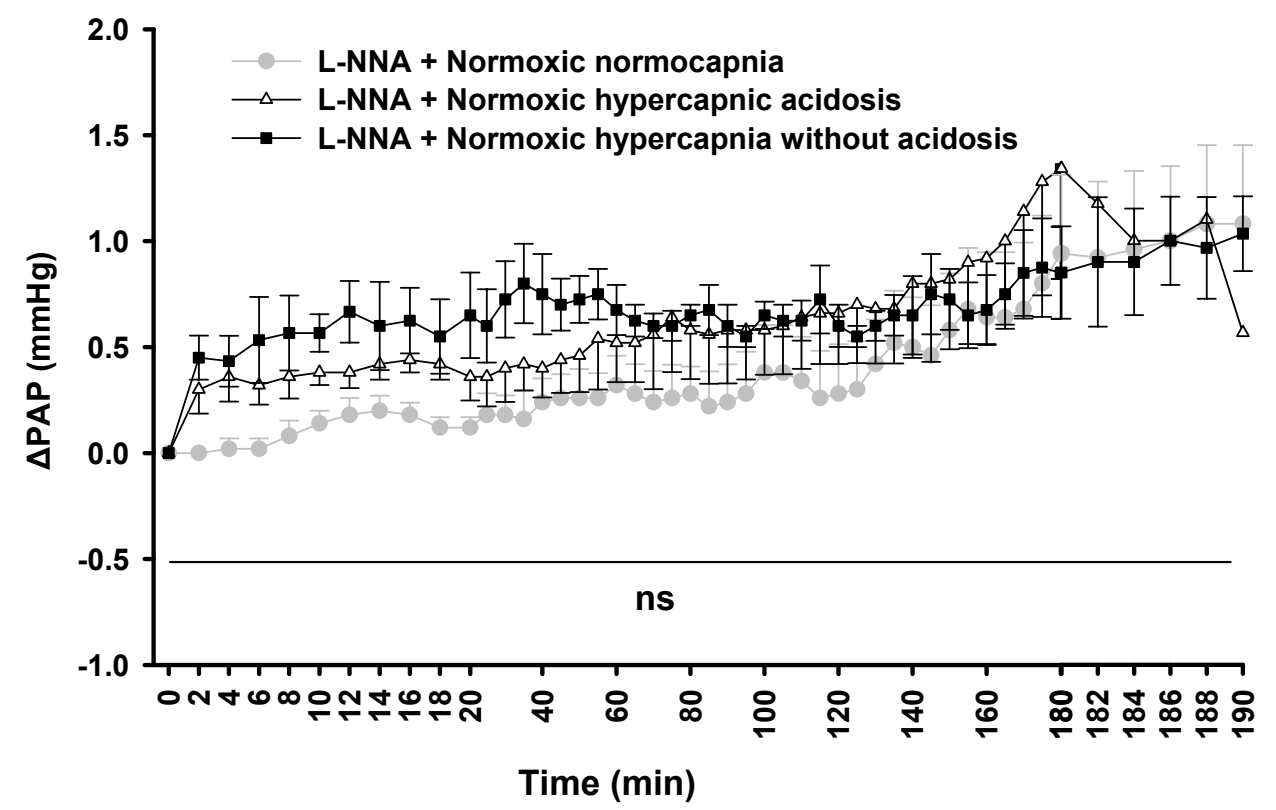

Figure 5 Effects of L-NNA on the strength of HPV during normocapnia and hypercapnia. $\triangle P A P$ values in the presence of L-NNA are

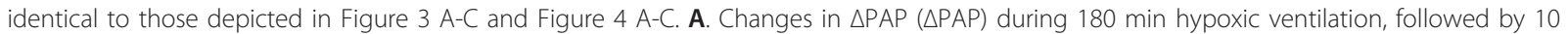
min ventilation with normoxic normocapnic gas. $\triangle P A P$ : change of PAP referenced to the baseline value at time set at zero. $\mathbf{B}$. Changes in PAP ( $\triangle \mathrm{PAP}$ ) during $190 \mathrm{~min}$ of normoxic ventilation. $\triangle \mathrm{PAP}$ : change of PAP referenced to the value at time set at zero. All data are mean \pm SEM. , significant difference $(P<0.05)$ between hypoxic hypercapnic acidosis and hypoxic hypercapnia without acidosis. 


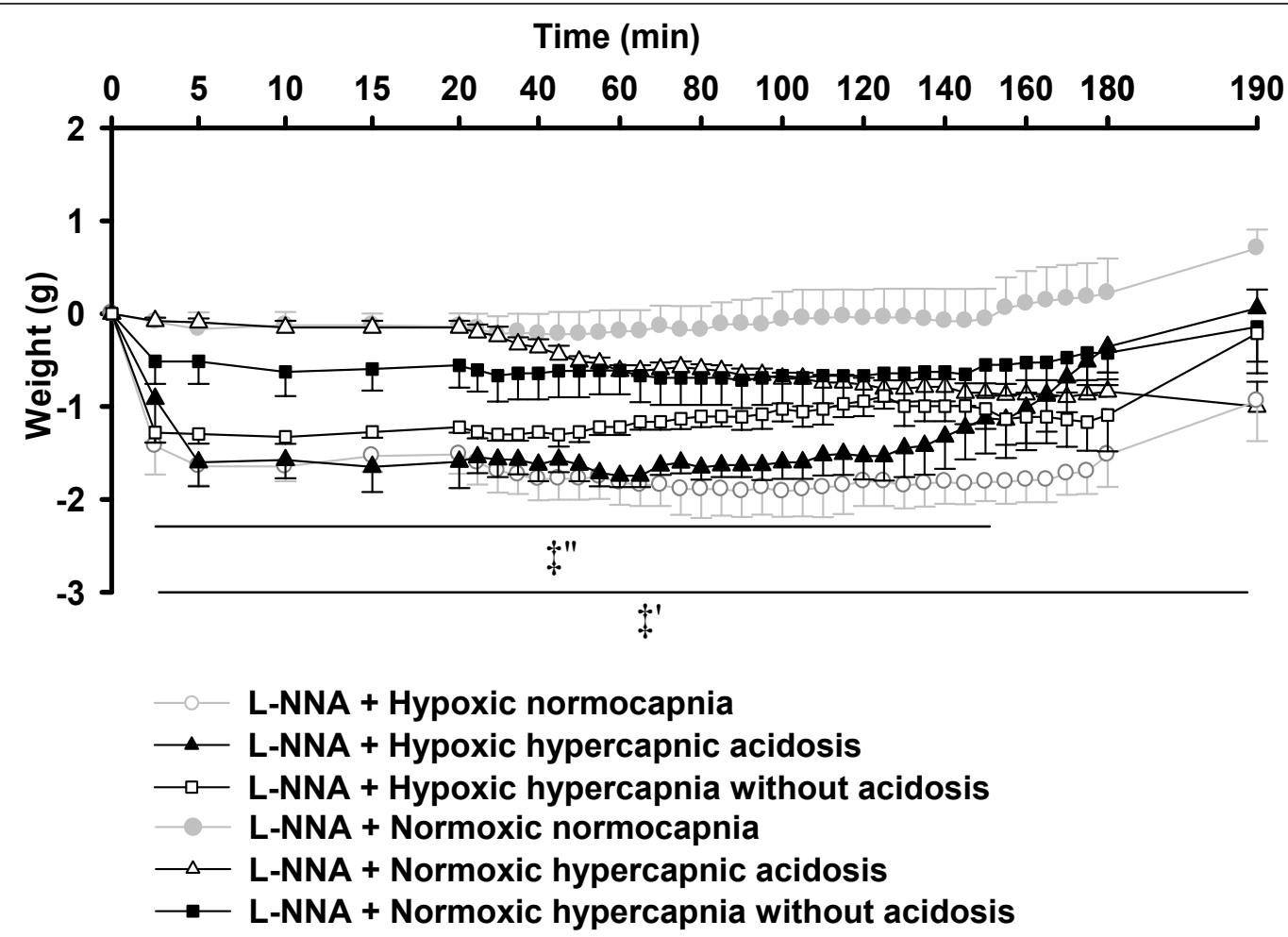

Figure 6 Effects of L-NNA on lung weight during normocapnia and hypercapnia. Lung weight changes of the respective experiments of figure 5. Data are mean \pm SEM. $\neq^{\prime}$, significant difference $(P<0.05)$ between hypoxic normocapnia and normoxic normocapnia. $\neq^{\prime \prime}$, significant difference $(P<0.05)$ between hypoxic hypercapnia with or without acidosis and normoxic normocapnia.

inconsistent findings, with studies differing from our data showing inhibition [28,29] or decrease of HPV [8].

Since, there were no statistically significant alterations in PAP during the entire period of exposure to normoxic hypercapnia, the increased $\triangle \mathrm{PAP}$ in the sustained phase of the hypoxic hypercapnic groups denotes to the potentiating effect of hypercapnia on the hypoxic response of pulmonary vasculature. In previous studies hypercapnia was reported to induce vasoconstriction in isolated rabbit lungs and rat arteries $[10,12,30]$, vasodilation in isolated rat lungs and arteries [31,32] or to have no effect on pulmonary vascular tone in isolated rat arteries $[9,11]$ in normoxia. There are, however, differences in experimental conditions and protocols that might explain these conflicting results.

Examining the role of NO, our study suggests 1 ) that NO counteracts the increase of PAP in both phases of HPV, but has no effect on pulmonary vascular tone under normoxic conditions, 2) that the increase of the sustained phase of HPV during hypoxic hypercapnia without acidosis, and partially during hypoxic normocapnia, is related to iNOS, whereas the increase in hypoxic hypercapnia with acidosis is related to eNOS, as during general NOS inhibition the significant increase of sustained HPV caused by hypercapnia with and without acidosis disappeared, whereas such an effect was only true for the iNOS inhibitor during hypercapnia without acidosis. This statement is, with regard to eNOS, however, only valid, if a potential role of nNOS can be neglected as suggested by measurements in nNOS knock-. out mice that showed no alteration of HPV and endothelial dependent or endothelial independent vasoconstriction in isolated lungs [33]. 3) Our data show that iNOS activity, but not eNOS activity is responsible for the increase in endothelial permeability occurring only during hypoxia without acidosis, as only the iNOS inhibitor, but not general NOS inhibition by L-NNA prevented the increase in the capillary filtration coefficient.

The first conclusion is based on the findings, that during normoxia inhibition of NOS by L-NNA did not change the level of vascular tone and inhibition of iNOS showed only a decrease of $\triangle \mathrm{PAP}$ during normoxic hypercapnia without acidosis at the beginning and increase of $\triangle \mathrm{PAP}$ at $\sim 60 \mathrm{~min}$ of the experiments. In contrast, L-NNA increased PAP during all conditions in hypoxia. As the iNOS inhibitor had not such an effect, most probably eNOS is responsible for this amplification of in acute and sustained HPV. In line with these findings it has been shown that NO is not involved in 
A

Acute phase

Sustained phase

Recovery

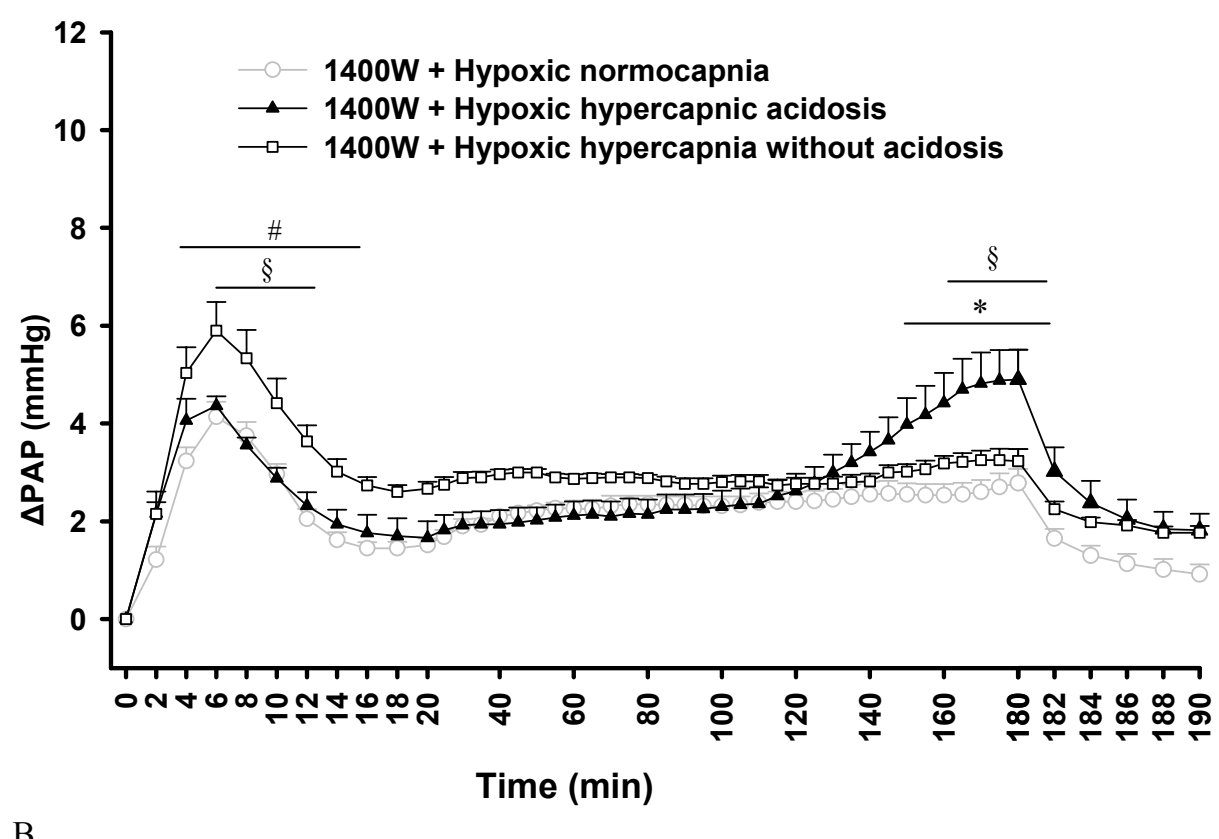

B

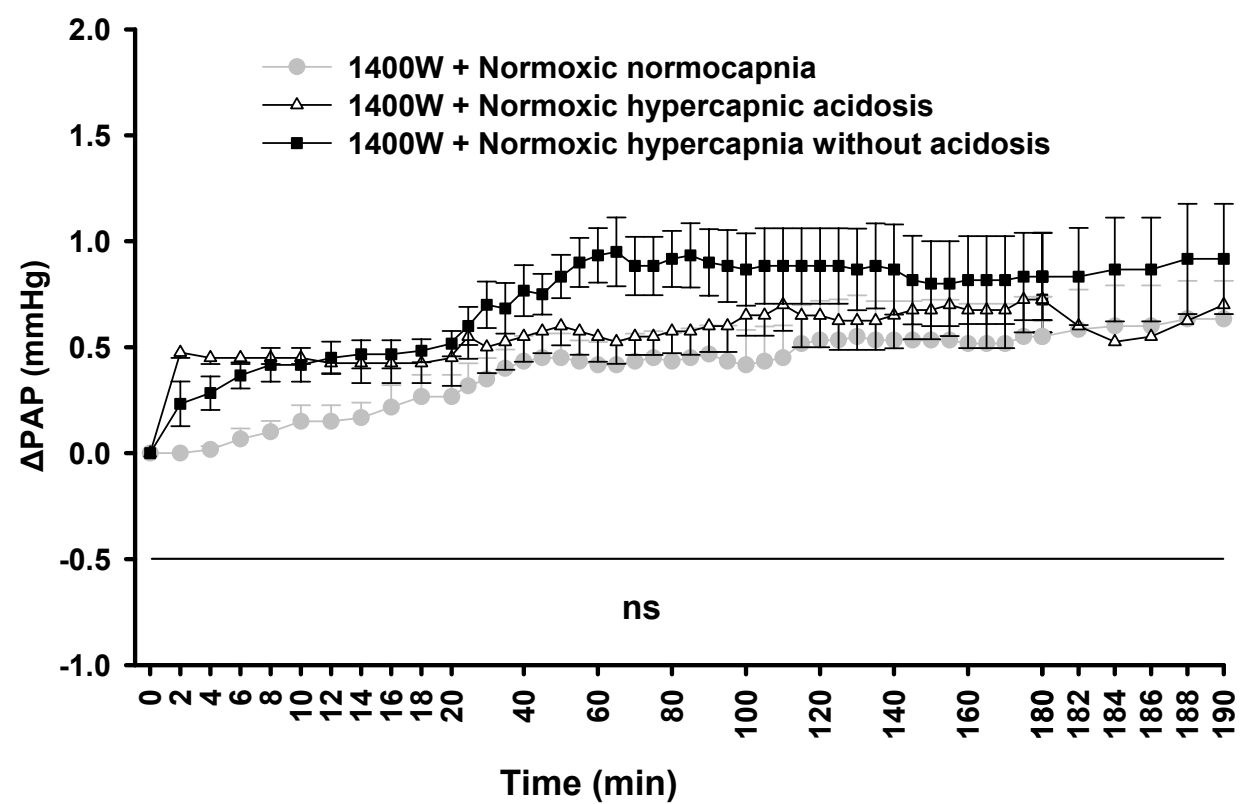

Figure 7 Effects of $1400 \mathrm{~W}$ on the strength of HPV during normocapnia and hypercapnia. $\triangle \mathrm{PAP}$ values in the presence of $1400 \mathrm{~W}$ are identical to those depicted in Figure 3 D-F and Figure 4 D-F. A. Changes in PAP ( $P$ PAP) during 180 min hypoxic ventilation, followed by 10 min ventilation with normoxic normocapnic gas. $\triangle \mathrm{PAP}$ : change of PAP referenced to the value at time set at zero. B. Changes of PAP ( $\triangle \mathrm{PAP})$ during 190 min of normoxic ventilation. $\triangle \mathrm{PAP}$ : change of PAP referenced to the value at time set at zero. All data are mean \pm SEM. ${ }^{*}$, significant difference $(P<0.05)$ between hypoxic normocapnia and hypoxic hypercapnic acidosis. \#, significant difference $(P<0.05)$ between hypoxic normocapnia and hypoxic hypercapnia without acidosis. $\S$, significant difference $(P<0.05)$ between hypoxic hypercapnic acidosis and hypoxic hypercapnia without acidosis. 


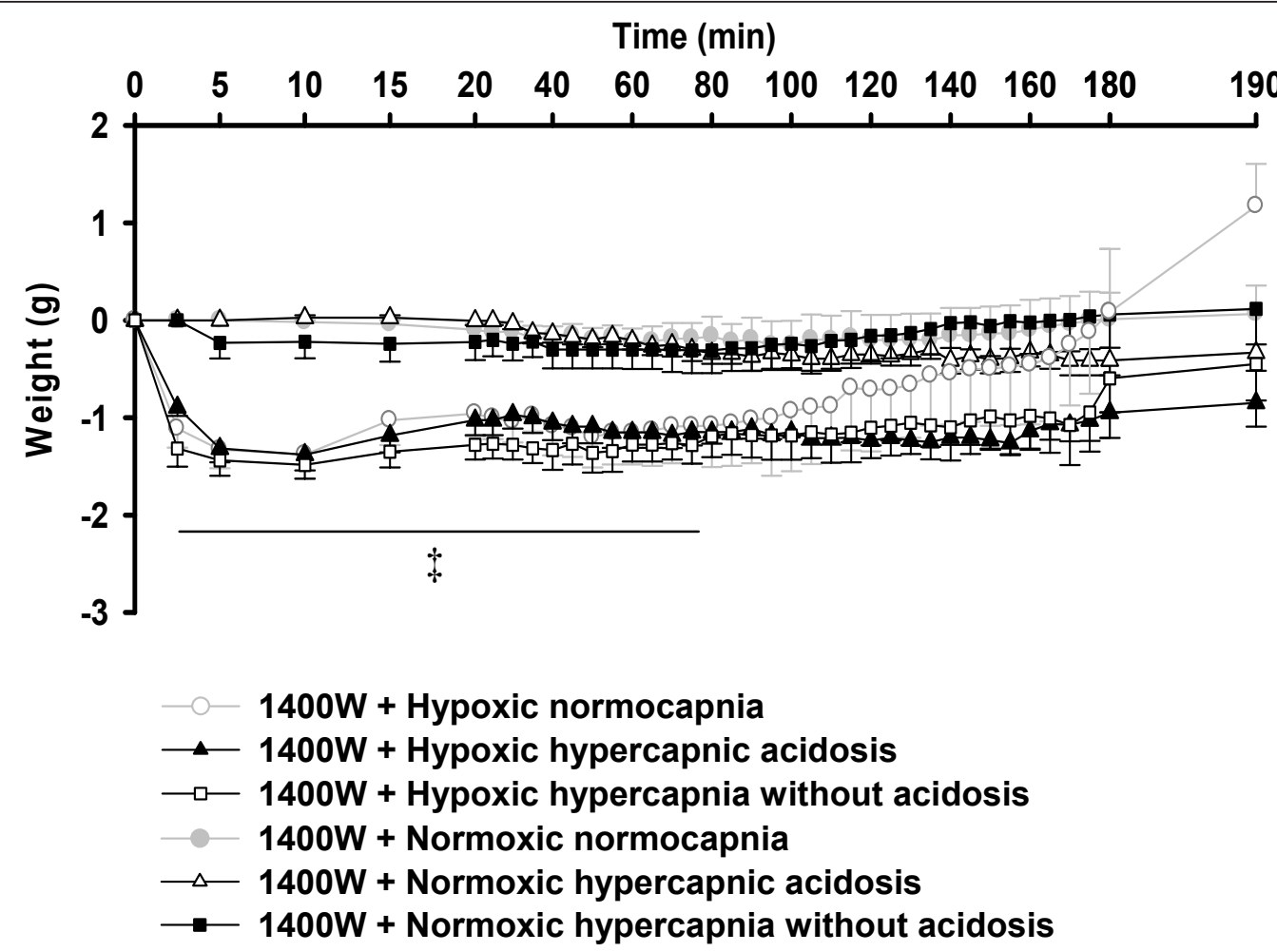

Figure $\mathbf{8}$ Effects of $1400 \mathrm{~W}$ on lung weight during normocapnia and hypercapnia. Lung weight changes of the respective experiments of figure 7. Data are mean \pm SEM. $\neq$, significant difference $(P<0.05)$ between hypoxic groups and normoxic normocapnia.

regulation of normoxic pulmonary vascular tone, neither during normocapnia $[34,35]$ nor during hypercapnia $[8,12]$, although some interspecies variability may exist $[34,36]$. Thus, NO is involved in the regulation of pulmonary vascular responses to hypoxia as previously shown $[5,36]$.

The second conclusion is based on the findings of differential amplification and inhibition of HPV, by general NOS inhibition with L-NNA and specific iNOS inhibition with $1400 \mathrm{~W}$, respectively. General NOS inhibition increased acute and sustained HPV in all conditions and eliminated the difference between hypoxic normocapnia and hypoxic hypercapnia with and without acidosis in sustained HPV. Specific iNOS inhibition only inhibited the difference between hypoxic normocapnia and hypoxic hypercapnia without acidosis in sustained HPV. Thus, eNOS may be responsible for the amplification of sustained HPV in hypercapnic acidosis, whereas iNOS may be responsible for the amplification of sustained HPV in hypercapnia without acidosis. Acute HPV, however, seems to be potentiated in hypercapnia without acidosis by different mechanisms than NO release. The fact that application of $1400 \mathrm{~W}$ did not alter $\triangle \mathrm{PAP}$ at early time points in hypoxia is consistent with a report of Resta et al. showing that iNOS does not modulate pulmonary vasoconstriction in response to a thromboxane analogue [37]. However, in sustained hypoxia $1400 \mathrm{~W}$ decreased $\triangle \mathrm{PAP}$ in hypoxic normocapnia and hypoxic hypercapnia without acidosis, which may be due to upregulation of iNOS in long term hypoxia, as shown before [37]. Uncoupled iNOS activity may lead to production of reactive oxygen and nitrogen species (ROS/RNS), which are suggested to increase HPV [38]. Hypercapnic acidosis may prevent such effects as sustained HPV was not changed in hypoxic hypercapnic acidosis. Along these lines decreased production of ROS and RNS has been shown in hypercapnic hypoxia [39]. Although we can only speculate about the effects of iNOS inhibition on $\triangle \mathrm{PAP}$ in normoxic hypercapnia without acidosis, the missing effect at late time points supports the finding of a specific activation of iNOS by hypercapnia without acidosis in hypoxia.

During hypoxia the biphasic increase of $\triangle \mathrm{PAP}$ is paralleled by a concomitant reduction in exhaled NO, as shown before for pure hypoxia by our laboratories [5]. The more pronounced decrease of NO during hypoxic hypercapnia correlated to increased sustained HPV compared to hypoxic normocapnia. However, elevated acute HPV in hypoxic hypercapnia without acidosis compared to hypercapnic acidosis did not correspond to a different NO release, which emphasizes the importance of other factors than NO transmitting the effects of hypercapnia 


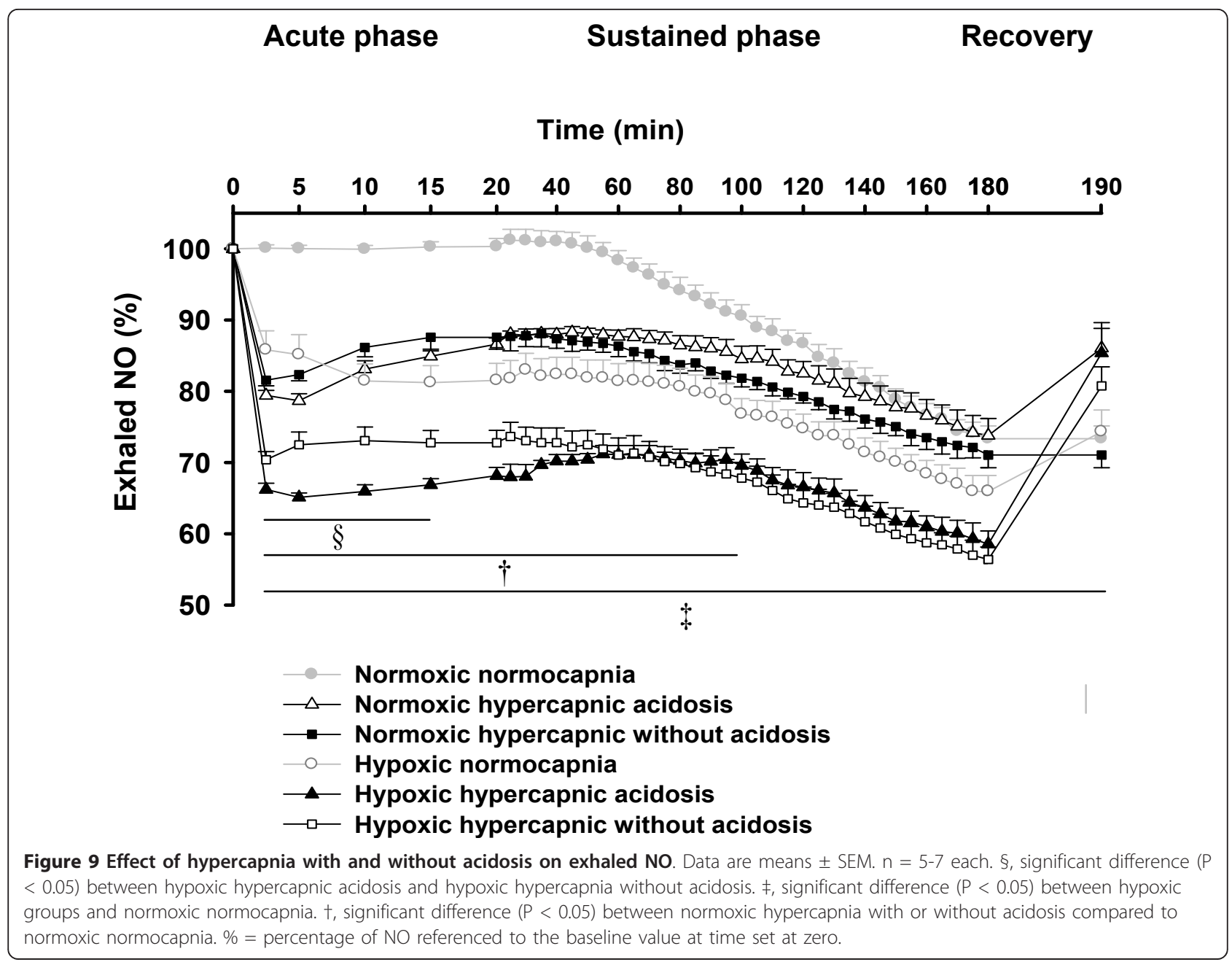

on acute HPV. In line with this explanation, inhibition of NO production did not potentiate short term HPV under hypercapnic acidosis $[22,40]$.

Our third conclusion is based on the findings that only hypercapnia without acidosis resulted in an increased capillary filtration coefficient $\left(\mathrm{K}_{\mathrm{fc}}\right)$ after sustained hypoxia. This effect is in accordance with findings that hypercapnic acidosis did not influence pulmonary capillary permeability in repetitive short term hypoxia $[13,41,42]$ or even decreased edema formation in acute lung injury, whereas buffering of hypercapnia with bicarbonate worsened lung injury [43]. This effect may be related to the acidosis induced by hypercapnia, as metabolic acidosis is known to be protective against ischemia-reperfusion induced lung injury in rat lungs [44]. Hypercapnia, in contrast, has been reported to exert damaging effects in the lung [21,23,45-48]. The increase in $\mathrm{K}_{\mathrm{fc}}$ during hypercapnia without acidosis could be inhibited by $1400 \mathrm{~W}$, but not by L-NNA in our study, being in line with previous studies showing that iNOS inhibition is protective against the cellular damage during hypercapnic acidosis [49]. Additionally, hypercapnia has been reported to induce injury in the fetal rat alveolar epithelial cells through a NO dependent pathway [21]. The increase in $\mathrm{K}_{\mathrm{fc}}$ during hypercapnia without acidosis in repetitive episodes of short term hypoxia, however, could also be inhibited by L-NNA [13], which indicates that sustained hypoxia rather activates iNOS than eNOS. The protective effect of iNOS inhibition on the $\mathrm{K}_{\mathrm{fc}}$ increase in hypercapnia without acidosis can, besides a direct effect of $\mathrm{NO}$ on endothelial integrity also (at least in part) be related to the decreased pulmonary artery pressure caused by $1400 \mathrm{~W}$ application.

\section{Conclusion}

Our study showed that hypercapnia with and without acidosis has different effects on the acute and sustained phase of HPV. Hypercapnic acidosis may have beneficial effects on ventilation-perfusion matching during prolonged hypoxia by increasing HPV and preserving pulmonary capillary integrity. However, it must also be 


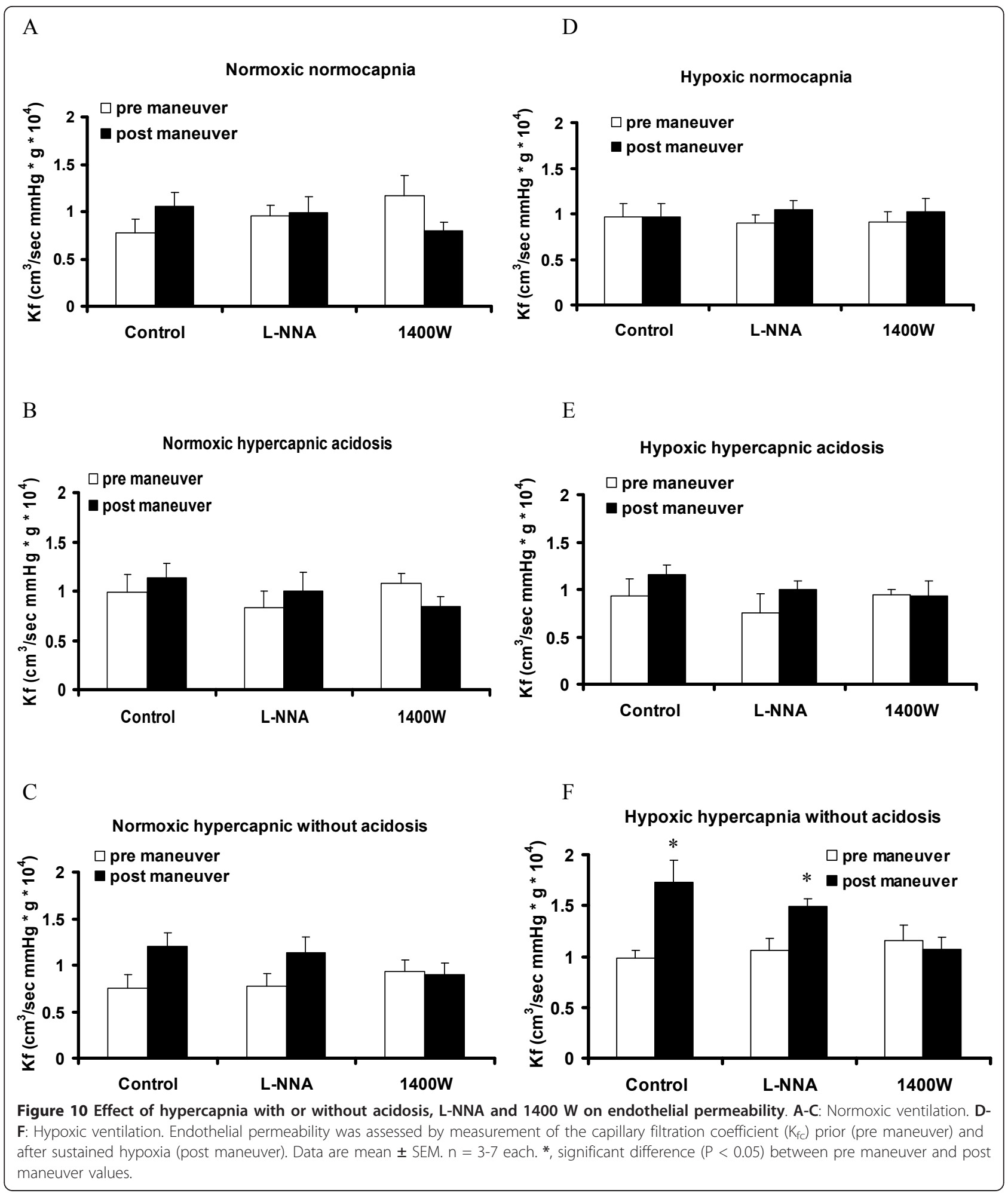

taken into account that prolonged hypoxic hypercapnia can facilitate right heart failure. As the hypoxia-induced increase in pulmonary vascular resistance is rather low $[50,51]$ this may be mainly important in predispositioned patients, if our findings are transferable to the human situation. Whereas general NOS inhibition increased acute and sustained HPV during normocapnia and hypercapnia with and without acidosis, iNOS inhibition 
decreased sustained HPV in normocapnia and hypercapnia without acidosis. In addition the increase of endothelial permeability in hypercapnia without acidosis can be attributed to increased iNOS activity.

\section{Acknowledgements}

This study was supported by the Research Council of Shiraz University of Medical Sciences, Shiraz, Iran (Grant 85-2801), and the Excellence Cluster Cardio-Pulmonary System (ECCPS).

Current affiliation of Bakytbek Egemnazarov: Duke University Medical Center, Department of Cardiology.

\section{Author details \\ ${ }^{1}$ School of Medicine, Shiraz University of Medical Sciences, Shiraz, Iran. ${ }^{2}$ Justus-Liebig-University Giessen, University of Giessen \& Marburg Lung Center (UGMLC), Excellence Cluster Cardio-Pulmonary System (ECCPS), Medical Clinic II/IVN, Aulweg 130, 35392 Giessen, Germany.}

\section{Authors' contributions}

FK carried out the experiments of isolated lungs and drafted the manuscript. NS analyzed and interpreted the data and drafted the manuscript. HG made substantial contribution to the conception and design of the study and revised the manuscript. WS made substantial contribution to the conception and design of the study and revised the manuscript. FG made substantial contribution to the conception and design of the study and revised the manuscript. BE participated in the experiments of the isolated lungs and drafted the manuscript. SM made substantial contribution to the conception and design of the study and revised the manuscript. GD made substantial contribution to the conception and design of the study and revised the manuscript. NW made substantial contribution to the conception and design of the study, analyzed and interpreted the data and revised the manuscript. All authors read and approved the final manuscript.

\section{Competing interests}

The authors declare that they have no competing interests.

Received: 24 October 2011 Accepted: 31 January 2012

Published: 31 January 2012

\section{References}

1. Ware $L B$, Matthay MA: The acute respiratory distress syndrome. N Engl J Med 2000, 342:1334-1349.

2. Zilberberg MD, Epstein SK: Acute lung injury in the medical ICU: comorbid conditions, age, etiology, and hospital outcome. Am J Respir Crit Care Med 1998, 157:1159-1164.

3. Wildman MJ, Sanderson C, Groves J, Reeves BC, Ayres J, Harrison D, Young D, Rowan K: Predicting mortality for patients with exacerbations of COPD and Asthma in the COPD and Asthma Outcome Study (CAOS). QJM 2009, 102:389-399.

4. Euler USV, Liljestrand G: Observations on the pulmonary arterial blood pressure in the cat. Acta Physiol Scand 1946, 12:301-320.

5. Weissmann N, Winterhalder S, Nollen M, Voswinckel R, Quanz K, Ghofrani HA, Schermuly RT, Seeger W, Grimminger F: NO and reactive oxygen species are involved in biphasic hypoxic vasoconstriction of isolated rabbit lungs. Am J Physiol Lung Cell Mol Physiol 2001, 280: L638-L645.

6. Barer GR, Shaw JW: Pulmonary vasodilator and vasoconstrictor actions of carbon dioxide. J Physiol 1971, 213:633-645.

7. Brimioulle $S$, Lejeune $P$, Vachiery JL, Leeman M, Melot C, Naeije R: Effects of acidosis and alkalosis on hypoxic pulmonary vasoconstriction in dogs. Am J Physiol 1990, 258:H347-H353.

8. Baudouin SV, Evans TW: Action of carbon dioxide on hypoxic pulmonary vasoconstriction in the rat lung: evidence against specific endotheliumderived relaxing factor-mediated vasodilation. Crit Care Med 1993, 21:740-746.

9. Sweeney M, Beddy D, Honner V, Sinnott B, O'Regan RG, McLoughlin P: Effects of changes in $\mathrm{pH}$ and $\mathrm{CO} 2$ on pulmonary arterial wall tension are not endothelium dependent. J Appl Physiol 1998, 85:2040-2046.
10. Lynch F, Sweeney M, O'Regan RG, McLoughlin P: Hypercapnia-induced contraction in isolated pulmonary arteries is endothelium-dependent. Respir Physiol 2000, 121:65-74.

11. Sweeney M, O'Regan RG, McLoughlin P: Effects of changes in $\mathrm{pH}$ and $\mathrm{PCO} 2$ on wall tension in isolated rat intrapulmonary arteries. Exp Physiol 1999, 84:529-539.

12. Vankova M, Snetkov VA, Knock GA, Aaronson PI, Ward JP: Euhydric hypercapnia increases vasoreactivity of rat pulmonary arteries via. Cardiovasc Res 2005, 65:505-512.

13. Ketabchi F, Egemnazarov B, Schermuly RT, Ghofrani HA, Seeger W, Grimminger F, Moosavi SMS, Dehghani GA, Weissmann N, Sommer N: Effects of hypercapnia with and without acidosis on hypoxic pulmonary vasoconstriction. Am J Physiol Lung Cell Mol Physiol 2009, 297:L977-L983.

14. Weissmann N, Sommer N, Schermuly RT, Ghofrani HA, Seeger W, Grimminger $\mathrm{F}$ : Oxygen sensors in hypoxic pulmonary vasoconstriction. Cardiovasc Res 2006, 71:620-629.

15. Ward JP, Robertson TP: The role of the endothelium in hypoxic pulmonary vasoconstriction. Exp Physiol 1995, 80:793-801.

16. Walmrath D, Schneider T, Pilch J, Grimminger F, Seeger W: Aerosolised prostacyclin in adult respiratory distress syndrome. Lancet 1993, 342:961-962.

17. Spriestersbach R, Grimminger F, Weissmann N, Walmrath D, Seeger W: Online measurement of nitric oxide generation in buffer-perfused rabbit lungs. J Appl Physiol 1995, 78:1502-1508.

18. Adding LC, Agvald P, Artlich A, Persson MG, Gustafsson LE: Betaadrenoceptor agonist stimulation of pulmonary nitric oxide production in the rabbit. Br J Pharmacol 1999, 126:833-839.

19. Stromberg S, Lonnqvist PA, Persson MG, Gustafsson LE: Lung distension and carbon dioxide affect pulmonary nitric oxide formation in the anaesthetized rabbit. Acta Physiol Scand 1997, 159:59-67.

20. Yamamoto $Y$, Nakano H, Ide H, Ogasa T, Takahashi T, Osanai S, Kikuchi K, Iwamoto J: Role of airway nitric oxide on the regulation of pulmonary circulation by carbon dioxide. J Appl Physiol 2001, 91:1121-1130.

21. Lang JD, Chumley P, Eiserich JP, Estevez A, Bamberg T, Adhami A, Crow J, Freeman BA: Hypercapnia induces injury to alveolar epithelial cells via a nitric oxide-dependent pathway. Am J Physiol Lung Cell Mol Physiol 2000, 279:L994-1002.

22. Yamaguchi K, Suzuki K, Naoki K, Nishio K, Sato N, Takeshita K, Kudo H, Aoki T, Suzuki Y, Miyata A, Tsumura H: Response of intra-acinar pulmonary microvessels to hypoxia, hypercapnic acidosis, and isocapnic acidosis. Circ Res 1998, 82:722-728.

23. Zhu S, Basiouny KF, Crow JP, Matalon S: Carbon dioxide enhances nitration of surfactant protein $\mathrm{A}$ by activated alveolar macrophages. Am J Physiol Lung Cell Mol Physiol 2000, 278:L1025-L1031.

24. Naoki K, Yamaquchi K, Suzuki K, Kudo H, Nishio K, Sato N, Takeshita K, Suzuki Y, Tsumura H: Nitric oxide differentially attenuates microvessel response to hypoxia and hypercapnia in injured lungs. Am J Physiol 1999, 277:R181-R189.

25. Weissmann N, Grimminger F, Walmrath D, Seeger W: Hypoxic vasoconstriction in buffer-perfused rabbit lungs. Respir Physiol 1995, 100:159-169.

26. Seeger $W$, Walmrath $D$, Menger $M$, Neuhof $H$ : Increased lung vascular permeability after arachidonic acid and hydrostatic challenge. J Appl Physiol 1986, 61:1781-1789.

27. Gordon JB, Rehorst-Paea LA, Hoffman GM, Nelin LD: Pulmonary vascular responses during acute and sustained respiratory alkalosis or acidosis in intact newborn piglets. Pediatr Res 1999, 46:735-741.

28. Brimioulle S, Vachiery JL, Lejeune P, Leeman M, Melot C, Naeije R: Acidbase status affects gas exchange in canine oleic acid pulmonary edema. Am J Physiol 1991, 260:H1080-H1086.

29. Marshall C, Lindgren L, Marshall BE: Metabolic and respiratory hydrogen ion effects on hypoxic pulmonary vasoconstriction. J Appl Physiol 1984, 57:545-550

30. Yamaguchi K, Takasugi T, Fujita H, Mori M, Oyamada Y, Suzuki K, Miyata A, Aoki T, Suzuki Y: Endothelial modulation of $\mathrm{pH}$-dependent pressor response in isolated perfused rabbit lungs. Am J Physiol 1996, 270 $\mathrm{H} 252-\mathrm{H} 258$

31. Sweeney M, O'Regan RG, McLoughlin P: Effects of hypercapnia on steady state, phenylephrine-induced tension in isolated rings of rat pulmonary artery. Adv Exp Med Biol 1996, 410:463-469. 
32. Viles $\mathrm{PH}$, Shepherd JT: Relationship between $\mathrm{pH}, \mathrm{Po} 2$, and $\mathrm{Pco} 2$ on the pulmonary vascular bed of the cat. Am J Physiol 1968, 215:1170-1176.

33. Fagan KA, Tyler RC, Sato K, Fouty BW, Morris KG, Huang PL, McMurtry IF, Rodman DM: Relative contributions of endothelial, inducible, and neuronal NOS to tone in the murine pulmonary circulation. Am J Physiol 1999, 277:L472-L478

34. Barnard JW, Wilson PS, Moore TM, Thompson WJ, Taylor AE: Effect of nitric oxide and cyclooxygenase products on vascular resistance in dog and rat lungs. J Appl Physiol 1993, 74:2940-2948.

35. Cremona G, Wood AM, Hall LW, Bower EA, Higenbottam T: Effect of inhibitors of nitric oxide release and action on vascular tone in isolated lungs of pig, sheep, dog and man. J Physiol 1994, 481(Pt 1):185-195.

36. Cremona G, Higenbottam T, Takao M, Hall L, Bower EA: Exhaled nitric oxide in isolated pig lungs. J Appl Physiol 1995, 78:59-63.

37. Resta TC, O'Donaughy TL, Earley S, Chicoine LG, Walker BR: Unaltered vasoconstrictor responsiveness after iNOS inhibition in lungs from chronically hypoxic rats. Am J Physiol 1999, 276:L122-L130.

38. Sommer N, Dietrich A, Schermuly RT, Ghofrani HA, Gudermann T, Schulz R, Seeger W, Grimminger F, Weissmann N: Regulation of hypoxic pulmonary vasoconstriction: basic mechanisms. Eur Respir J 2008, 32:1639-1651.

39. Chovanec M, Novotna J, Wilhelm J, Hampl V, Vizek M, Herget J: Hypercapnia attenuates hypoxic pulmonary hypertension by inhibiting lung radical injury. Physiol Res 2009, 58(Suppl 2):S79-S85

40. Dumas M, Dumas JP, Rochette L, Advenier C, Giudicelli JF: Comparison of the effects of nicorandil, pinacidil and nitroglycerin on hypoxic and hypercapnic pulmonary vasoconstriction in the isolated perfused lung of rat. Br J Pharmacol 1996, 117:633-638.

41. Bouvet F, Dreyfuss D, Lebtahi R, Martet G, Le GD, Saumon G: Noninvasive evaluation of acute capillary permeability changes during high-volume ventilation in rats with and without hypercapnic acidosis. Crit Care Med 2005, 33:155-160.

42. Haberkern CM, Bland RD: Effect of hypercapnia on net filtration of fluid in the lungs of awake newborn lambs. J Appl Physiol 1981, 51:423-427.

43. Laffey JG, Engelberts D, Kavanagh BP: Buffering hypercapnic acidosis worsens acute lung injury. Am J Respir Crit Care Med 2000, 161:141-146.

44. Moore TM, Khimenko PL, Taylor AE: Restoration of normal pH triggers ischemia-reperfusion injury in lung by $\mathrm{Na}+/ \mathrm{H}+$ exchange activation. $\mathrm{Am}$ J Physiol 1995, 269:H1501-H1505.

45. Lang JD, Figueroa M, Sanders KD, Aslan M, Liu YL, Chumley P, Freeman BA: Hypercapnia via reduced rate and tidal volume contributes to lipopolysaccharide-induced lung injury. Am J Respir Crit Care Med 2005, 171:147-157.

46. Feihl F, Eckert P, Brimioulle $S$, Jacobs $O$, Schaller MD, Melot C, Naeije R: Permissive hypercapnia impairs pulmonary gas exchange in the acute respiratory distress syndrome. Am J Respir Crit Care Med 2000, 162:209-215

47. Brochard L, Roudot-Thoraval F, Roupie E, Delclaux C, Chastre J, FernandezMondejar E, Clémenti E, Mancebo J, Factor P, Matamis D, Ranieri M, Blanch L, Rodi G, Mentec H, Dreyfuss D, Ferrer M, Brun-Buisson C, Tobin M, Lemaire F: Tidal volume reduction for prevention of ventilator-induced lung injury in acute respiratory distress syndrome. The Multicenter Trail Group on Tidal Volume reduction in ARDS. Am J Respir Crit Care Med 1998, 158:1831-1838.

48. O'Brodovich HM, Stalcup SA, Pang LM, Lipset JS, Mellins RB: Bradykinin production and increased pulmonary endothelial permeability during acute respiratory failure in unanesthetized sheep. $J$ Clin Invest 1981, 67:514-522.

49. Pedoto A, Caruso JE, Nandi J, Oler A, Hoffmann SP, Tassiopoulos AK McGraw DJ, Camporesi EM, Hakim TS: Acidosis stimulates nitric oxide production and lung damage in rats. Am J Respir Crit Care Med 1999, 159:397-402.

50. Grunig E, Weissmann S, Ehlken N, Fijalkowska A, Fischer C, Fourme T, Galié N, Ghofrani A, Harrison RE, Huez S, Humbert M, Janssen B, Kober J, Koehler R, Machado RD, Mereles D, Naeije R, Olschewski H, Provencher S, Reichenberger F, Retailleau K, Rocchi G, Simonneau G, Torbicki A, Trembath R, Seeger W: Stress Doppler echocardiography in relatives of patients with idiopathic and familial pulmonary arterial hypertension: results of a multicenter European analysis of pulmonary artery pressure response to exercise and hypoxia. Circulation 2009, 119:1747-1757.
51. Beard JT, Newman JH, Loyd JE, Byrd BF III: Doppler estimation of changes in pulmonary artery pressure during hypoxic breathing. J Am SoC Echocardiogr 1991, 4:121-130.

doi:10.1186/1465-9921-13-7

Cite this article as: Ketabchi et al: Effects of hypercapnia and NO synthase inhibition in sustained hypoxic pulmonary vasoconstriction. Respiratory Research 2012 13:7.

\section{Submit your next manuscript to BioMed Central and take full advantage of:}

- Convenient online submission

- Thorough peer review

- No space constraints or color figure charges

- Immediate publication on acceptance

- Inclusion in PubMed, CAS, Scopus and Google Scholar

- Research which is freely available for redistribution

Submit your manuscript at www.biomedcentral.com/submit
Biomed Central 